\title{
Optimization of Ilmenite Dissolution by Synergistic Effect of Oxalic Acid and Hydrochloric Acid for Preparing Synthetic Rutile
}

\author{
Mohammad Hasan Omidi ${ }^{1}$, Omid Salmani Nuri2 ${ }^{*}$, Hassan Tavakoli \\ ${ }^{1}$ Department of Chemistry, Faculty of Science, University of Guilan, Guilan, Iran \\ ${ }^{2}$ Department of Mining and Metallurgical Engineering, Amirkabir University of Technology, Tehran, Iran \\ ${ }^{3}$ Department of Physics and Chemistry, Faculty of Basic Sciences, Imam Ali University, Tehran, Iran \\ Email: *omidnuri@aut.ac.ir
}

How to cite this paper: Omidi, M.H., Nuri, O.S. and Tavakoli, H. (2018) Optimization of Ilmenite Dissolution by Synergistic Effect of Oxalic Acid and Hydrochloric Acid for Preparing Synthetic Rutile. International Journal of Nonferrous Metallurgy, 7, 25-38.

https://doi.org/10.4236/ijnm.2018.73003

Received: May 30, 2018

Accepted: July 28, 2018

Published: July 31, 2018

Copyright $\odot 2018$ by authors and Scientific Research Publishing Inc. This work is licensed under the Creative Commons Attribution International License (CC BY 4.0).

http://creativecommons.org/licenses/by/4.0/

\begin{abstract}
This study was carried out to investigate the interaction of oxalic acid with hydrochloric acid to attain the better performance for iron dissolution in comparison to absence of oxalic acid. The effects of oxalic acid on ratio of hydrochloric acid, acid concentration, ratio of liquid to solid, temperature and dissolution time are investigated for the dissolution of Fe and Ti from ilmenite to produce synthetic rutile. The DX7 software basing on an experimental design method with the central composite of response surface design is applied to specify the effects of the parameters and to optimize the leaching process. The optimum condition was determined by analysis of variance (ANOVA), indicating that the ratio of oxalic acid to hydrochloric acid for $\mathrm{Fe}$ dissolution and acid concentration for Ti dissolution were the most effective parameters. The results showed that the dissolution of $\mathrm{Fe}$ and $\mathrm{Ti}$ in 30\% (w/w) hydrochloric acid solution was only $48.65 \%$ and $5.14 \%$, respectively, while at the same condition and in the presence of oxalic acid with twice the ratio, these values are increased to $78.65 \%$ and $12.06 \%$, respectively. The optimum values of parameters were as follows: oxalic acid to hydrochloric acid ratio (2:1), acid concentration (30\%), ratio of liquid to solid (10), temperature $\left(160^{\circ} \mathrm{C}\right)$, and dissolution time $(3 \mathrm{~h})$. By applying the optimized parameters, $\mathrm{Fe}$ and $\mathrm{Ti}$ dissolution of $97.15 \%$ and $2.8 \%$ were predicted by the software with a desirability of 0.745 . The results of leaching tests indicated that the Fe and $\mathrm{Ti}$ dissolution of $97.58 \%$ and $2.43 \%$, were achieved, respectively, which are very close to the predicted value.
\end{abstract}




\section{Keywords}

Ilmenite, Oxalic Acid, Hydrochloric Acid, Synthetic Rutile, Leaching

\section{Introduction}

Ilmenite $\left(\mathrm{FeTiO}_{3}\right)$ is one of the titanium mineral resources ranking second after rutile $\left(\mathrm{TiO}_{2}\right)$ in titanium industries [1] [2] [3]. Today, the high-grade sources of titanium minerals such as rutile are diminishing; hence, for the low-grade ores like ilmenite an attempt is made to convert ilmenite into synthetic rutile [4]. Ilmenite can be upgraded to synthetic rutile using different methods of pyrometallurgy [4] [5] [6] [7], hydrometallurgy [8] [9] [10] [11], and electrometallurgy [12]. Despite some problems, utilizing the hydrothermal processes for ilmenite ore is more preferable. This is due to low energy consumption and the production of high quality $\mathrm{TiO}_{2}$ products [12]. Many researches have reported the application of the hydrothermal process for ilmenite. Direct leaching of ilmenite can be performed using inorganic acids or organic ones. Different scholars investigated the leaching of ilmenite by sulfuric and hydrochloric acids at different conditions of acid dosages, temperatures, acid to ore ratios, particle size, and etc. [13] [14] [15] [16] [17].

Iron is the most important impurity through the production of synthetic rutile. The removal of iron content by inorganic acids requires a high temperature and high concentration of acid. Therefore, the organic acids can be used as the iron removing agents. On the other hand, most of these studies were concerned with the extraction of titania from ilmenite by $\mathrm{H}_{2} \mathrm{SO}_{4}$ and $\mathrm{HCl}$ [10] [11] [14] [16] [17], whereas few of the mare directed towards extracting titania by interaction with organic acid reagents. Martínez-Luévanos et al. stated that oxalic acid can be selected as the leaching agent when in comparison to other organic acids such as citric, malonic and acetic acids. This was due to the special properties of oxalic acid, including higher acidity, complexion power, and the reduction ability [18]. Also, oxalic acid has been used as the iron removing agent from silica in the presence of sulfuric acid. The results showed that the iron extraction was about $35 \%$ to $45 \%$ in the presence of $3 \mathrm{~kg} /$ ton of oxalic acid and $2 \mathrm{~kg} / \mathrm{ton}$ of sulfuric acid, whereas in the same condition and only in presence of sulfuric acid, it was about $3 \%$ to $9 \%$ [19]. The dissolution of ilmenite by oxalic acid has been reported by Woranart et al. The results showed that $86.4 \%$ of titanium is leached by $4 \mathrm{~mol} / \mathrm{L}$ of oxalic acid, 1:20 solid/liquid ratio, and $90^{\circ} \mathrm{C}$ temperature, while in the same condition and $4 \mathrm{~mol} / \mathrm{L}$ of sulfuric acid, the dissolution of titanium was 16.1\% [20]. Some scholars reported that the capacity of oxalic acid in Fe dissolution is more than that of sulfuric acid, chloric acid, nitric acid and other organic acids [21] [22] [23].

A few decades ago, testing, interpretation, and presentation of laboratory results were boring, expensive, time consuming, and also demanding; while sam- 
ple collection and preparation were overwhelming. To end that, experimental design methodology was introduced. The statistical design is an effective tool in the classification, optimization and modeling of a process [24] [25] [26].

The aim of this study was to investigate the effect of chloric acid in the presence and absence of oxalic acid through ilmenite leaching. The study outlines the optimization of parameters affecting the process and evaluation of the product. In order to understand and optimize the leaching process, the DX7 software was applied basing on statistical methods of experiments via central composite design at two levels of parameters [27].

\section{Materials and Methods}

\subsection{Materials}

The ilmenite ore samples were prepared from Qara-Aghaj deposits in northwest of Iran. After crushing and grinding the samples to $80 \%$ minus 63 microns, these samples are purified in different stages of magnetic separation and gravity separation methods. All the solid samples were characterized by powder X-ray diffraction (XRD) to check for phase purity using a Scanting diffractometer (model XDS 2000) with $\mathrm{Cu} \mathrm{Ka}$ radiation (Figure 1). The results of chemical analysis via $\mathrm{X}$-ray fluorescence $(\mathrm{XRF})$ showed that the composition of the ilmenite was: $\mathrm{Fe}$ total 17\%; $\mathrm{TiO}_{2} 46.2 \% ; \mathrm{CaO} 0.38 \% ; \mathrm{MgO} 2.53 \% ; \mathrm{MnO} 1.04 \% ; \mathrm{SiO}_{2} 0.19 \% ; \mathrm{Al}_{2} \mathrm{O}_{3}$ $0.44 \%$; other elements $1.34 \%$, respectively (Table 1 ).

\subsection{Methods}

Acid leaching of ilmenite ore was carried out using $\mathrm{HCl}$ acid with a concentration of $37 \%(\mathrm{w} / \mathrm{w})$ and oxalic acid with a concentration of $99 \%(\mathrm{w} / \mathrm{w})$ in a 300 $\mathrm{cm}^{3}$ three-neck glass reactor equipped with a reflux condenser and a mechanical agitator with Teflon-coated stirring rod. A stirring speed of 560 RPM was applied to keep the slurry suspended during the leaching experiment. After reaching the desired temperature, a $20 \mathrm{~g}$ ilmenite ore sample was added. After the

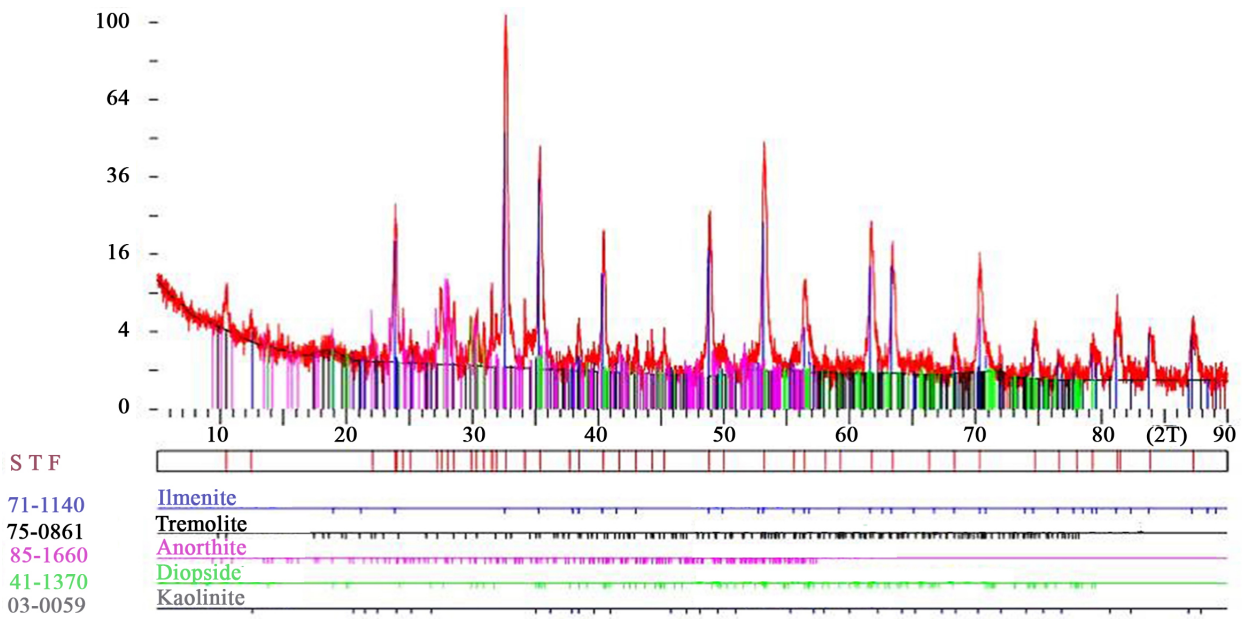

Figure 1. XRD pattern of the sample. 
Table 1. Chemical composition of ilmenite concentrate (Wt \%).

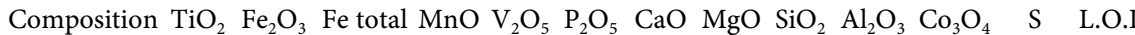

$\begin{array}{llllllllllllll}\text { Purified Il } & 46.2 & 48.6 & 17 & 1.04 & 0.29 & 0.24 & 0.38 & 2.53 & 0.19 & 0.44 & 0.025 & 0.024 & 0.0\end{array}$

required reaction period, the slurry was filtered off. After washing the solid titanium with $2 \% \mathrm{HCl}$, the filtrated sample was dried in the air at $100^{\circ} \mathrm{C}$.

The UV-Vis spectroscopy method was used to determine the Fe content of the samples. Therefore, after diluting the sample, $0.1 \mathrm{ml}$ of the sample was poured into the $10 \mathrm{ml}$ flask and $0.5 \mathrm{ml}$ of sulfosalicylic acid was added. After stirring the solution, $0.5 \mathrm{ml}$ of ammonia was added and the absorbance was recorded at 425 $\mathrm{nm}$. Total iron and ferrous iron were determined spectrophotometrically using the phenanthroline method at a wavelength $515 \mathrm{~nm}$ [28]. In this research, the effects of five parameters were studied in the leaching process. Thus, the leaching tests were carried out to evaluate the accuracy of the prediction in optimum conditions and validation of the process. Acid concentration (\%), oxalic acid to hydrochloric acid ratio, ratio of solid to liquid $(\mathrm{S} / \mathrm{L})(\mathrm{g} / \mathrm{L})$, temperature $\left({ }^{\circ} \mathrm{C}\right)$, and dissolution time (h) are used as the input parameters of the software. A software based experimental design approach (DX7) was applied at two levels of parameters to determine and model optimization through the central composite design method. The lower and upper limits of those parameters were delineated in tests and are depicted in Table 2. The designed experiments by DX7 software are shown in Table 3.

\section{Results and Discussion}

After entering the results of leaching tests which are obtained from the calculation conditions in the software, the optimum conditions of Fe and Ti dissolution from ilmenite were delineated. Software calculations showed the effective parameters (Table 3 ) and probability plot (Figure 2) with regard to responses.

From the software, the terms in the model would have a significant effect on the response if the Prob > F value is less than 0.05. There are two methods to evaluate the model accuracy: 1) residual normal plot, and 2) residual amounts vs. the predicted values.

The model can estimate the test values with appropriate precision when the obtained residuals have a normal distribution. Figure 2 shows the absolute values of residual differences between the test residuals and achieved response from the model.

As shown in Figure 2(a), Figure 2(b), the obtained results from the model have a good fit with the results of experiments. The lack of particular trends in residual values vs. the test numbers showed that there are not any systematic errors in performing the tests. Systematic errors led to an increase or decrease in the residual values.

Table 4 demonstrates the ANOVA contained responses. The ANOVA is built entirely on the premise that the factors are fixed, not random and the design is 
Table 2. The lower and upper limits of five parameters.

\begin{tabular}{cccc}
\hline Factor & Name & Lowe level & High level \\
\hline A & [Oxalic acid:sulfuric acid] & 0 & 2 \\
B & Acid concentration $(\% \mathrm{w} / \mathrm{w})$ & 10 & 30 \\
C & Ratio of liquid to solid $(\mathrm{g} / \mathrm{L})$ & 5 & 10 \\
D & Temperature $\left({ }^{\circ} \mathrm{C}\right)$ & 70 & 160 \\
E & Dissolution time $(\mathrm{h})$ & 2 & 4 \\
\hline
\end{tabular}

Table 3. Designed experiments by DX7 software.

\begin{tabular}{|c|c|c|c|c|c|c|c|}
\hline Run & $\begin{array}{c}\text { [Oxalic: } \\
\text { Hydrochloric] } \\
\text { acid ratio }\end{array}$ & $\begin{array}{c}\text { Acid } \\
\text { concentration } \\
(\%)\end{array}$ & $\begin{array}{l}\text { Liquid/Solid } \\
\text { (g/L) }\end{array}$ & $\begin{array}{c}\text { Temperature } \\
\left({ }^{\circ} \mathrm{C}\right)\end{array}$ & $\begin{array}{l}\text { Time } \\
\text { (h) }\end{array}$ & $\begin{array}{c}\mathrm{Fe} \\
\text { dissolution } \\
(\%)\end{array}$ & $\begin{array}{c}\mathrm{Ti} \\
\text { dissolution } \\
(\%)\end{array}$ \\
\hline 1 & 2 & 30 & 10 & 70 & 2 & 82 & 17 \\
\hline 2 & 1 & 20 & 7.5 & 115 & 3 & 61 & 7.6 \\
\hline 3 & 0 & 10 & 10 & 160 & 4 & 44 & 4.5 \\
\hline 4 & 1 & 20 & 7.5 & 160 & 3 & 71 & 11.5 \\
\hline 5 & 2 & 10 & 10 & 160 & 2 & 81 & 12 \\
\hline 6 & 2 & 30 & 5 & 70 & 4 & 90 & 8.2 \\
\hline 7 & 0 & 10 & 5 & 70 & 4 & 24 & 2.1 \\
\hline 8 & 1 & 20 & 7.5 & 115 & 3 & 60 & 5.5 \\
\hline 9 & 1 & 20 & 7.5 & 115 & 3 & 61 & 5.3 \\
\hline 10 & 2 & 10 & 10 & 70 & 4 & 78 & 11.1 \\
\hline 11 & 0 & 10 & 10 & 70 & 2 & 28 & 3 \\
\hline 12 & 1 & 20 & 7.5 & 70 & 3 & 55 & 4.9 \\
\hline 13 & 0 & 30 & 5 & 160 & 4 & 42 & 14.5 \\
\hline 14 & 1 & 20 & 7.5 & 115 & 3 & 65 & 11.3 \\
\hline 15 & 0 & 30 & 5 & 70 & 2 & 26 & 11.3 \\
\hline 16 & 2 & 10 & 5 & 70 & 2 & 65 & 8.2 \\
\hline 17 & 0 & 20 & 7.5 & 115 & 3 & 47 & 9.4 \\
\hline 18 & 2 & 30 & 5 & 160 & 2 & 77 & 16 \\
\hline 19 & 0 & 30 & 10 & 70 & 4 & 40 & 19 \\
\hline 20 & 1 & 20 & 5 & 115 & 3 & 55 & 6.7 \\
\hline 21 & 1 & 20 & 7.5 & 115 & 2 & 50 & 7.9 \\
\hline 22 & 2 & 20 & 7.5 & 115 & 3 & 77 & 10.2 \\
\hline 23 & 2 & 10 & 5 & 160 & 4 & 72 & 13.5 \\
\hline 24 & 1 & 20 & 7.5 & 115 & 4 & 78 & 13.7 \\
\hline 25 & 2 & 30 & 10 & 160 & 4 & 95 & 39 \\
\hline 26 & 1 & 20 & 7.5 & 115 & 3 & 67 & 7.8 \\
\hline 27 & 1 & 10 & 7.5 & 115 & 3 & 38 & 6.8 \\
\hline
\end{tabular}




\section{Continued}

\begin{tabular}{cccccccc}
\hline 28 & 0 & 30 & 10 & 160 & 2 & 53 & 4.8 \\
29 & 1 & 20 & 10 & 115 & 3 & 73 & 15 \\
30 & 1 & 20 & 7.5 & 115 & 3 & 62 & 7.5 \\
31 & 1 & 30 & 7.5 & 115 & 3 & 65 & 11.1 \\
32 & 0 & 10 & 5 & 160 & 2 & 34 & 4.3 \\
\hline
\end{tabular}

Table 4. ANOVA results of the equation for the responses by DX7.

\begin{tabular}{ccccccc}
\hline Model & S.D. & C.V\% & R squared & Adeq precision & F value & P value (Prob $>$ F) \\
\hline Fe dissolution & 3.34 & 5.53 & 0.9856 & 27.298 & 49.27 & $<0.0001$ \\
Ti dissolution & 2.27 & 22 & 0.9301 & 25.019 & 21.08 & $<0.0001$ \\
\hline
\end{tabular}
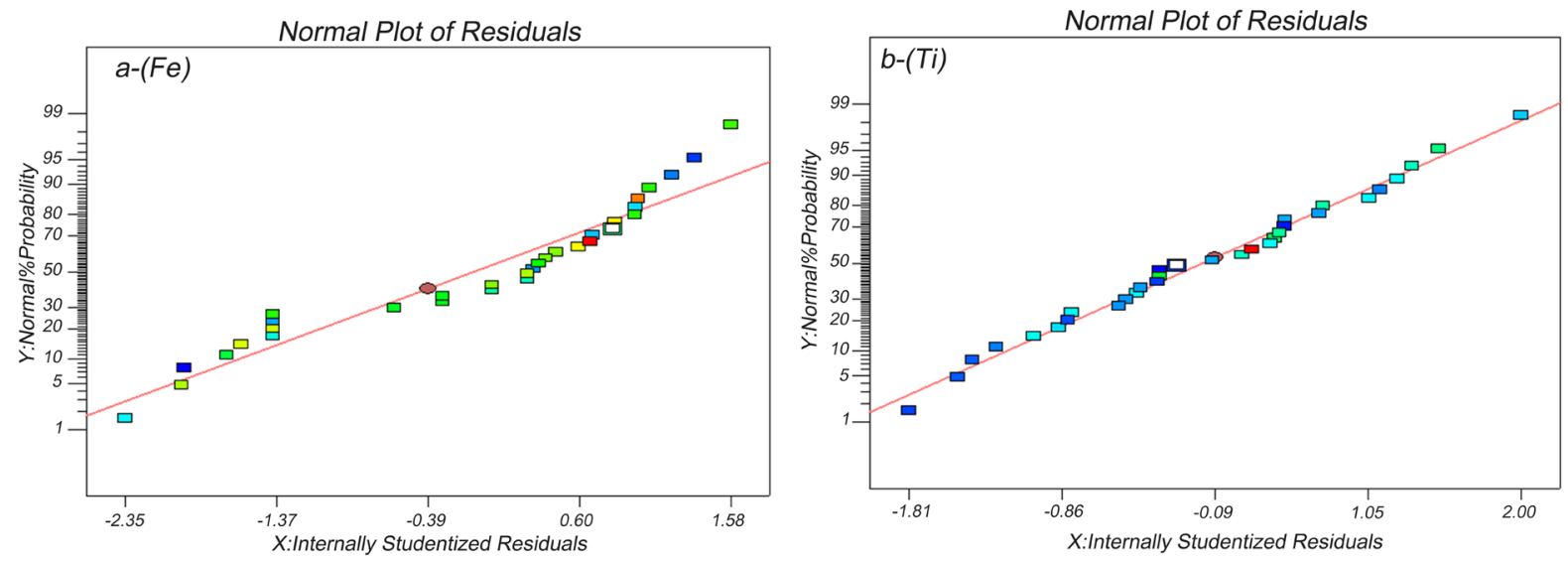

Figure 2. Normal plot of residual for (a) Fe dissolution (b) Ti dissolution.

crossed, not nested. ANOVA makes it possible to check that the assumed model fits well with the experimental points. The small probability of p-values $(0.05$ or less) calls for rejection of the null hypothesis. The Fe and Ti model f-values of 49.27 and 21.08 , implied by the model, respectively were significant. There is only a $0.01 \%$ chance that the "model f-values" of these large values could occur due to the noise. As to the p-values, it is noteworthy that the probability of errors in the preferred model for the leaching of ilmenite was less than $0.01 \%$. The model adeq precision is based on the signal to noise ratio, according to which a ratio greater than 4 is desirable, and the ratio of 27.298 and 25.019 indicated the adequate signals. Therefore, these models can be used to navigate the design space.

\subsection{Synergistic Effect of Oxalic Acid and Hydrochloric Acid}

Figure 3 shows the effect of varying ratios of oxalic acid to hydrochloric acid at different levels of 0,1 and 2. The experimental data indicated that the dissolution of iron is strictly increased by increasing the oxalic acid to hydrochloric acid ratio (Figure 3(a)). Also, the percentage of iron dissolution was higher than that of 


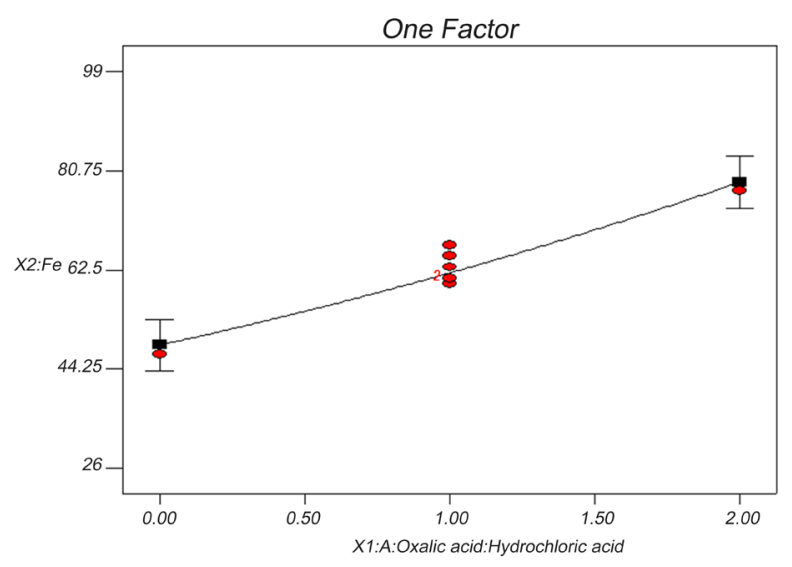

(a)

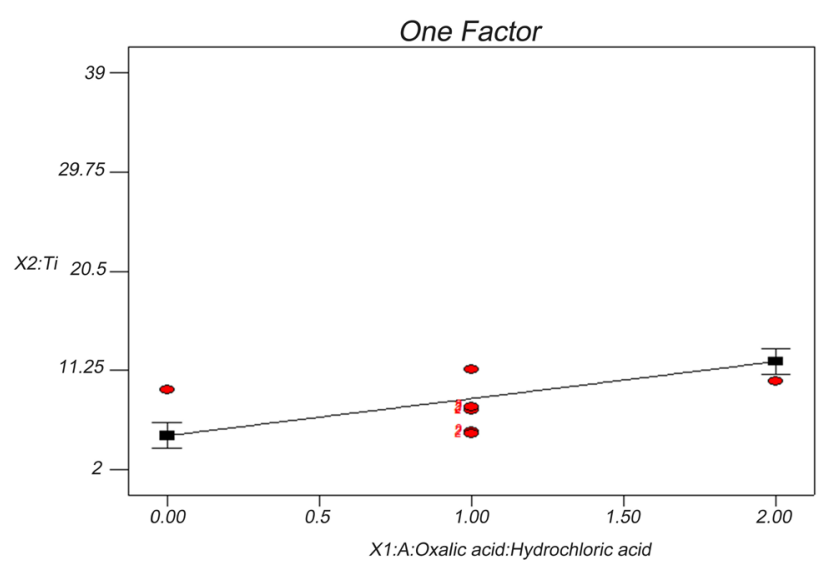

(b)

Figure 3. Effect of Oxalic acid:Hydrochloric acid ratios as a significant parameter on (a) Fe dissolution (b) Ti dissolution.

titanium dissolution, which is in good agreement with the findings of Lasheen [29].

The results showed that by increasing the ratio between the oxalic and hydrochloric acids from 0 to 2 at moderate levels of other factors (acid concentration: $20 \%, \mathrm{~L} / \mathrm{S}$ ratio: 7.5 , temperature: $115^{\circ} \mathrm{C}$, time: $3 \mathrm{~h}$ ), one can increase the dissolution of $\mathrm{Fe}$ and $\mathrm{Ti}$ from $48.65 \%$ and $5.14 \%$ to $78.65 \%$ and $12.06 \%$, respectively (Figure 3(a), Figure 3(b)). It is noteworthy that this factor was involved in an interaction with the acid concentration factor.

The mechanisms of ilmenite reactions with hydrochloric acid areas reactions 1 to 3 and Oxalic acid dissociates according to the reactions 4 and 5 .

$$
\begin{gathered}
\mathrm{FeTiO}_{3}+4 \mathrm{HCl} \rightarrow \mathrm{TiOCl}_{2}+\mathrm{FeCl}_{2}+2 \mathrm{H}_{2} \mathrm{O} \\
\mathrm{Fe}_{2} \mathrm{O}_{3}+6 \mathrm{HCl} \rightarrow 2 \mathrm{FeCl}_{3}+3 \mathrm{H}_{2} \mathrm{O} \\
\mathrm{TiOCl}_{2}+\mathrm{H}_{2} \mathrm{O} \rightarrow \mathrm{TiO}_{2}+2 \mathrm{HCl} \\
\mathrm{H}_{2} \mathrm{C}_{2} \mathrm{O}_{4} \longleftrightarrow \mathrm{H}^{+}+\mathrm{HC}_{2} \mathrm{O}_{4}^{-}, K_{a_{1}}=5.378 * 10^{-2} \\
\mathrm{HC}_{2} \mathrm{O}_{4}^{-} \longleftrightarrow \mathrm{H}^{+}+\mathrm{C}_{2} \mathrm{O}_{4}^{2-}, K_{a_{2}}=5.42 * 10^{-5}
\end{gathered}
$$

According to reaction (4), $\mathrm{H}_{2} \mathrm{C}_{2} \mathrm{O}_{4}$ is a good chelating agent and has a strong acidic effect. The protons producing according to the reactions (4 and 5) attacks to $\mathrm{Fe}^{3+}$ and $\mathrm{Fe}^{2+}$ ions particles and formed the water-soluble compounds (reactions 8 and 9) [21].

$$
\begin{gathered}
\mathrm{Fe}_{2} \mathrm{O}_{3}+6 \mathrm{H}^{+} \longleftrightarrow 2 \mathrm{Fe}^{3+}+3 \mathrm{H}_{2} \mathrm{O} \\
\mathrm{Fe}^{3+}+\mathrm{C}_{2} \mathrm{O}_{4}^{2-} \longleftrightarrow \mathrm{Fe}\left(\mathrm{C}_{2} \mathrm{O}_{4}\right)^{+} \quad K=5.89 * 10^{8} \\
\mathrm{Fe}\left(\mathrm{C}_{2} \mathrm{O}_{4}\right)^{+}+\mathrm{C}_{2} \mathrm{O}_{4}^{2-} \longleftrightarrow \mathrm{Fe}\left(\mathrm{C}_{2} \mathrm{O}_{4}\right)_{2}^{-} \quad K=3.31 * 10^{6} \\
\mathrm{Fe}\left(\mathrm{C}_{2} \mathrm{O}_{4}\right)_{2}^{-}+\mathrm{C}_{2} \mathrm{O}_{4}^{2-} \longleftrightarrow \mathrm{Fe}\left(\mathrm{C}_{2} \mathrm{O}_{4}\right)_{3}^{3-} \quad K=2.75 * 10^{4}
\end{gathered}
$$

The reason for improving the $\mathrm{Fe}$ dissolution in the presence of oxalate ions can be due to the high capacity of oxalic acid in Fe mobilization [23]. Oxalate ions can form a strong bidentate ligand with Lewis acid Fe centers and labilize 
the Fe-O bond, whereas hydrochloric acid form weak complexes with Fe in the aqueous phase [23]. Fe(III) oxalate complex can improve the dissolution of iron ions via facilitating the electron transfer between dissolved $\mathrm{Fe}$ (II) and surface $\mathrm{Fe}(\mathrm{III})$ [30]. Therefore, presence of oxalic acid can improve the dissolution of iron.

\subsection{Effect of Acid Concentration}

Acid concentration is an important parameter, controlling the rate of leaching process. The leaching tests were carried out at different concentration of acids varying from 10 to $30 \%(\mathrm{w} / \mathrm{w})$. The results showed that the dissolution of Fe and Ti from ore are increased by increasing the acid concentration from $10 \%$ to $30 \%$ (Figure 4(a), Figure 4(b)). It was due to increasing the number of oxalate and chloride ions interacting with a surface of the dissolving solid with increasing the acid concentration. As shown in Figure 4, the dissolution of Fe and $\mathrm{Ti}$ goes up from $39.65 \%$ and $4.41 \%$ to $66.65 \%$ and $12.79 \%$ at the aforementioned condition, respectively. It shows that the oxalic acid is a good iron dissolution agent along with the hydrochloric acid.

\subsection{Effect of Liquid to Solid Ratio (L/S)}

The liquid to solid ratio is the other factor affecting the leaching process. Leaching tests were performed at different L/S ratios (ranging from 5, 7.5 and 10). The results showed that the dissolution of $\mathrm{Ti}$ and $\mathrm{Fe}$ from ilmenite are increased by increasing the L/S ratio (Figure 5). It was due to low hydrolyzing the titanium dioxide [31] [32] [33] [34]. The low levels of L/S ratio result in precipitating the titanium in the pores and preventing the formation of $\mathrm{TiOCl}_{2}$ species as a dissolved ones [33].

\subsection{Effect of Temperature}

The experiments were carried out at different temperatures varying from $70^{\circ} \mathrm{C}$

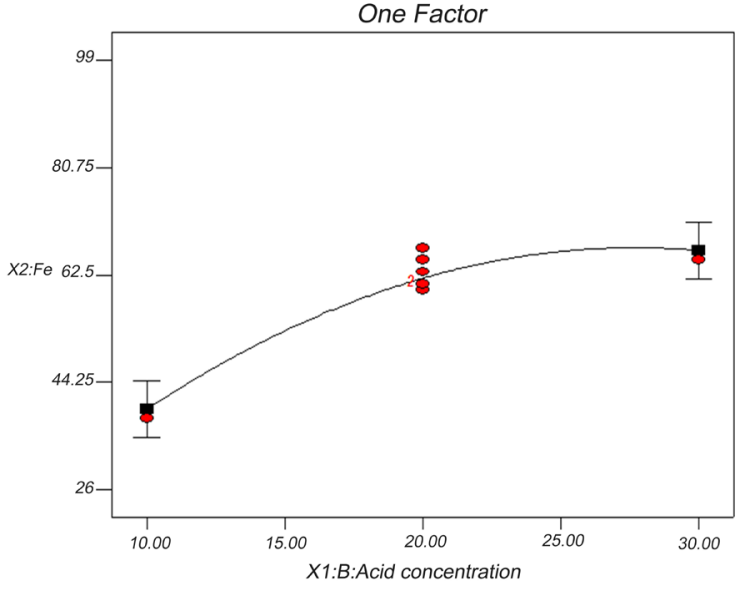

(a)

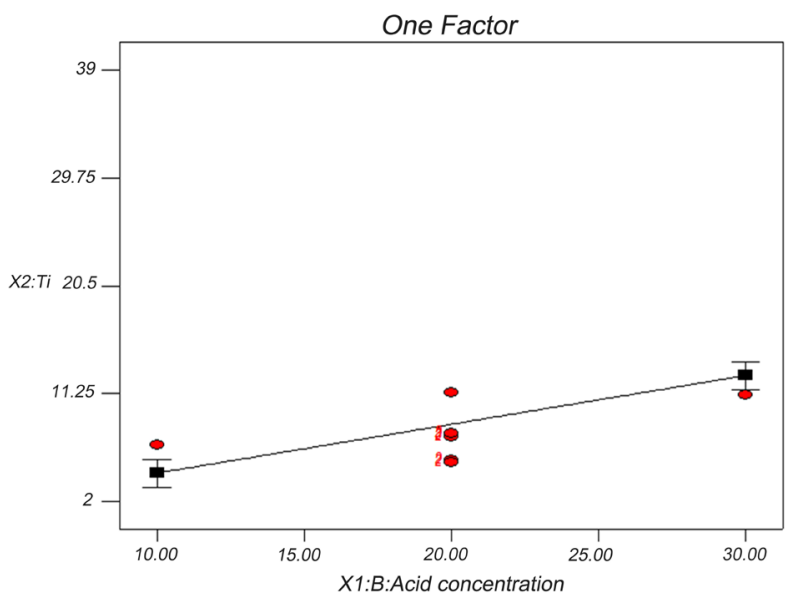

(b)

Figure 4. Effect of acid concentration on (a) Fe dissolution (b) Ti dissolution. 


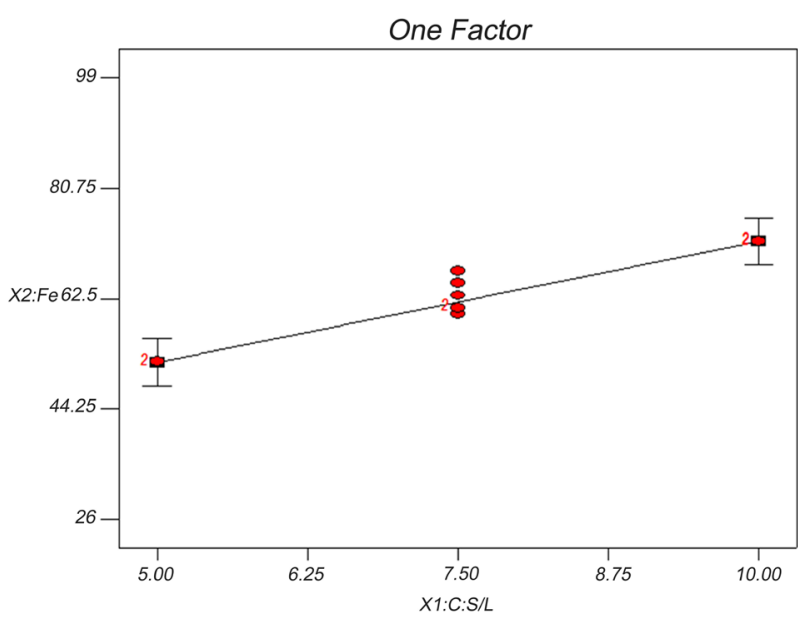

(a)

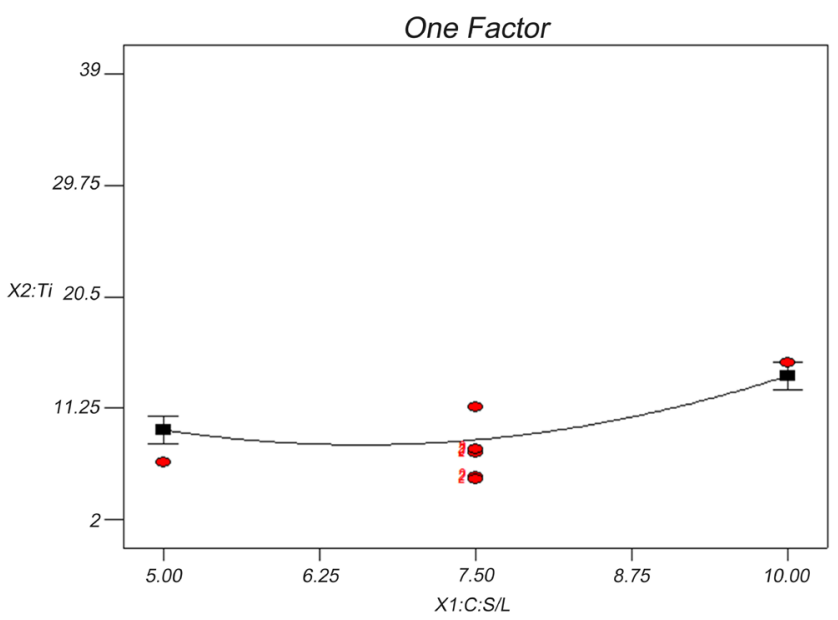

(b)

Figure 5. Effect of L/S ratio on (a) Fe dissolution (b) Ti dissolution.

to $160^{\circ} \mathrm{C}$. Inasmuch as the temperatures below the boiling point has not very effective on the Fe extraction and Ti recovery [35]. Therefore, some experiments were performed at $160^{\circ} \mathrm{C}$.

As shown from Figure 6(a) and Figure 6(b), the dissolution of $\mathrm{Fe}$ and $\mathrm{Ti}$ at higher temperatures (up to the boiling point) are significant. These were not only due to the fast polymerization of ilmenite and hydrolysis the $\mathrm{TiOCl}_{2}$ at high temperature, but also the exothermic nature of Fe dissolution from ore [31] [32] [35].

\subsection{Effect of Dissolution Time}

In order to investigate the effect of dissolution time on $\mathrm{Fe}$ and $\mathrm{Ti}$ dissolution, leaching tests were performed for 2, 3 and $4 \mathrm{~h}$ (Figure 7(a) and Figure 7(b)). It is clear from Figure 7(a) and Figure 7(b), increasing the time result in increasing the Fe dissolution and Ti recovery [35]. It is expected that after long times there will be a little dissolution in Fe and Ti content of ore [32].

\subsection{Synergistic Effect of Factors}

The results of models showed that the interaction of oxalic acid: hydrochloric acid ratio with acid concentration and liquid to solid ratio were the significant factors on the dissolution of $\mathrm{Fe}$ and $\mathrm{Ti}$ (Figure 8). It can be understood that the presence of oxalic acid as a solvent agent reinforces the dissolution of Fe. The Ti dissolution from ilmenite can be mainly attributed to hydrochloric acid because the previous works of scholars proved that the oxide of $\mathrm{Ti}$ was not dissolved in $\mathrm{H}_{2} \mathrm{C}_{2} \mathrm{O}_{4}$ solution [21]. Also, it is apparent that the dissolution of iron is strongly influenced by the interaction of the parameters.

According to Equation (1) and Equation (2), it is indicated that the dependency of Fe dissolution on the presence of oxalic acid and Ti dissolution on acid concentration is more rather than that of other factors. Also, the interaction of factors is considerable. 


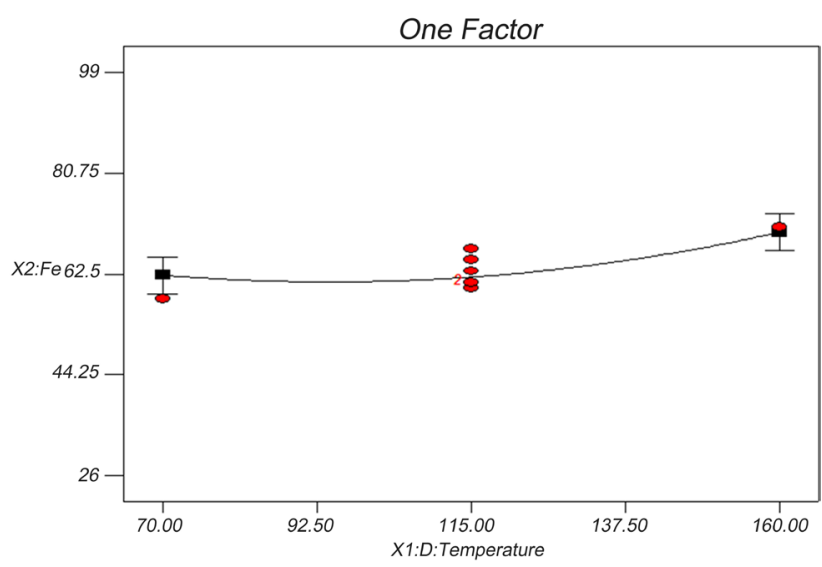

(a)

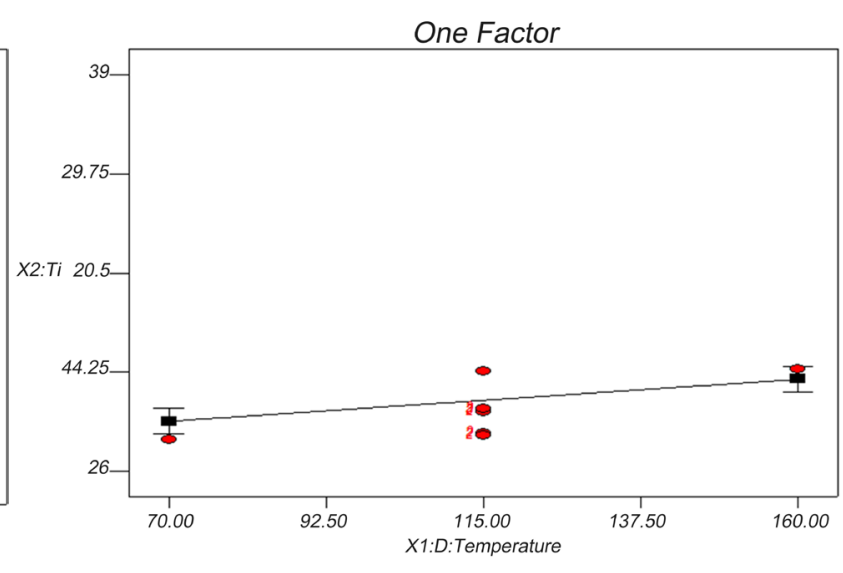

(b)

Figure 6. Effect of temperature on (a) Fe dissolution (b) Ti dissolution.

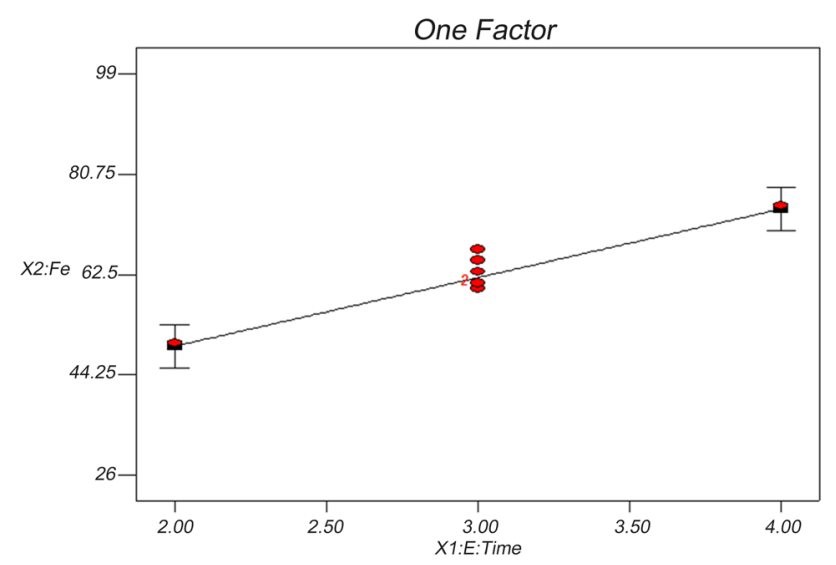

(a)

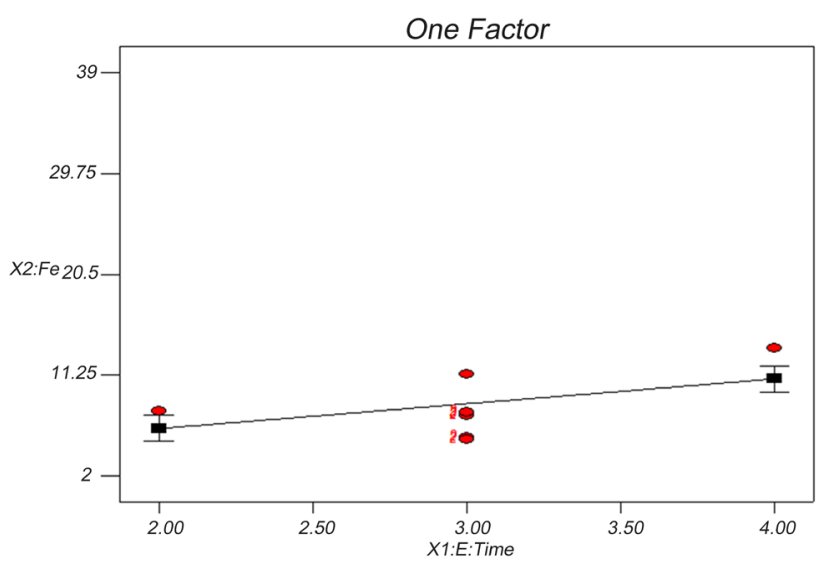

(b)

Figure 7. Effect dissolution time on (a) Fe dissolution (b) Ti dissolution.

The final equations for the dissolution of Fe and Ti from ilmenite ore in terms of coded factors of the model are given by Equation (10) and Equation (11):

$\mathrm{Fe}$ dissolution $=61.94+15.00 \mathrm{~A}+13.50 \mathrm{~B}+10.00 \mathrm{C}+3.89 \mathrm{D}+12.50 \mathrm{E}+2.19 \mathrm{AB}+0.69 \mathrm{AC}(10)$

$\mathrm{Ti}$ dissolution $=8.61+3.46 \mathrm{~A}+4.19 \mathrm{~B}+2.26 \mathrm{C}+1.96 \mathrm{D}+2.28 \mathrm{E}-0.19 \mathrm{AB}+2.13 \mathrm{AC}(11)$

A comparison the phase purity of leaching residue and feed sample using a XRD pattern showed that the XRD peaks at the angle of 32 degrees, related to ilmenite, completely disappeared and turned into the synthetic rutile (Figure 9).

\section{Conclusions}

This work studied the effect of different parameters on the dissolution of iron and titanium from ilmenite in the oxalic acid and hydrochloric acid solution. The results showed that the most significant parameters in the leaching tests for iron dissolution were as follows:

Ratio of oxalic acid to sulfuric acid (2:1), Acid concentration (30\% w/w), dissolution time $(4 \mathrm{~h})$, ratio of liquid to solid $(10)$, and temperature $\left(160^{\circ} \mathrm{C}\right)$ with standardized effect values of $15,13.5,12.5,10$, and 3.89 , respectively. 


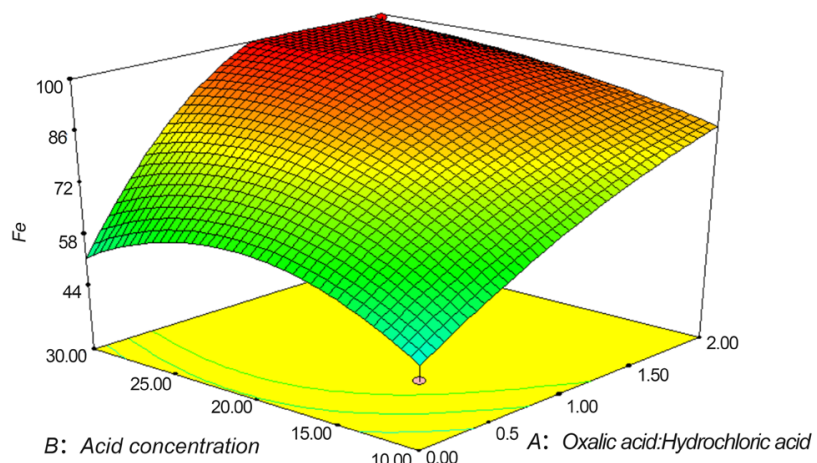

(a)

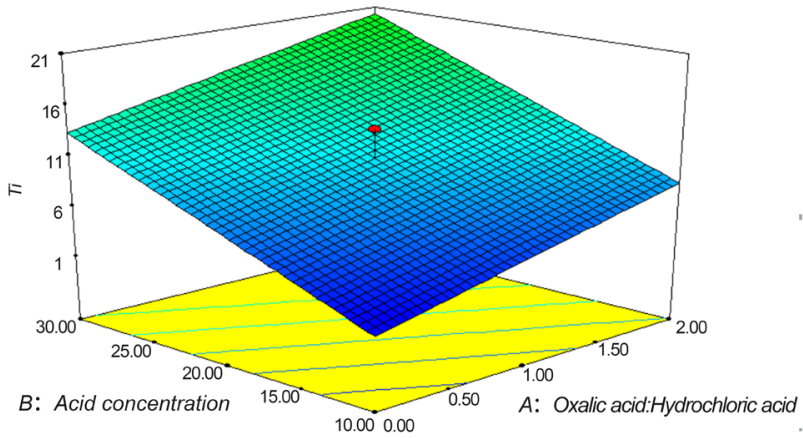

(c)

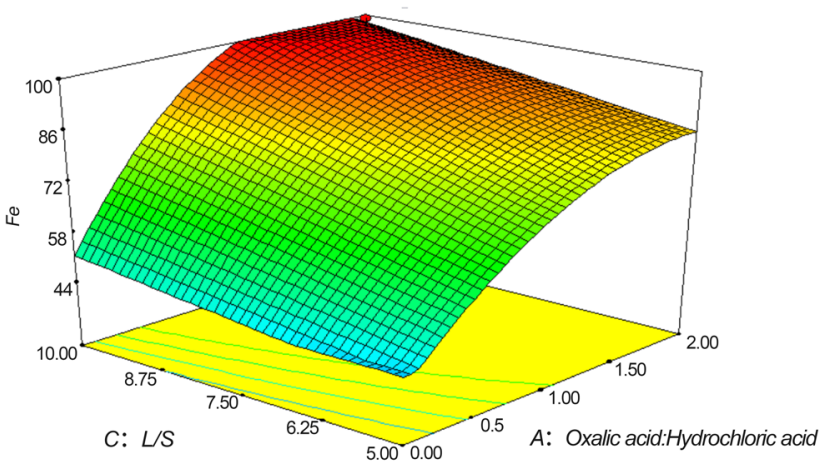

(b)

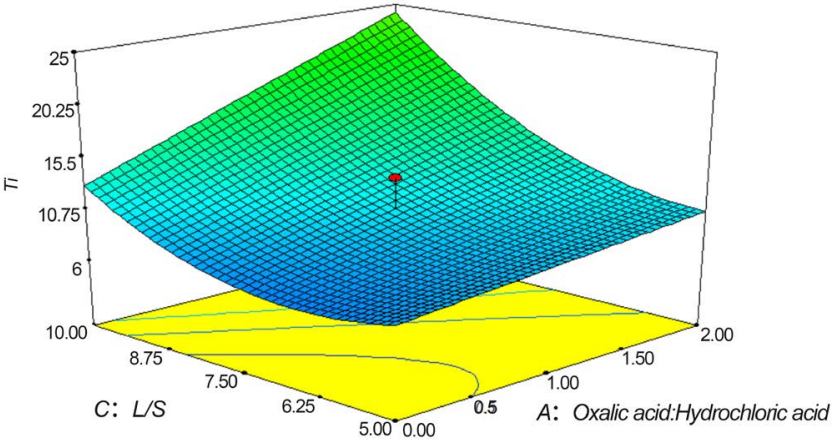

(d)

Figure 8. Interaction of factors A, B and C on ((a), (b)) Fe dissolution ((c), (d)) Ti dissolution.

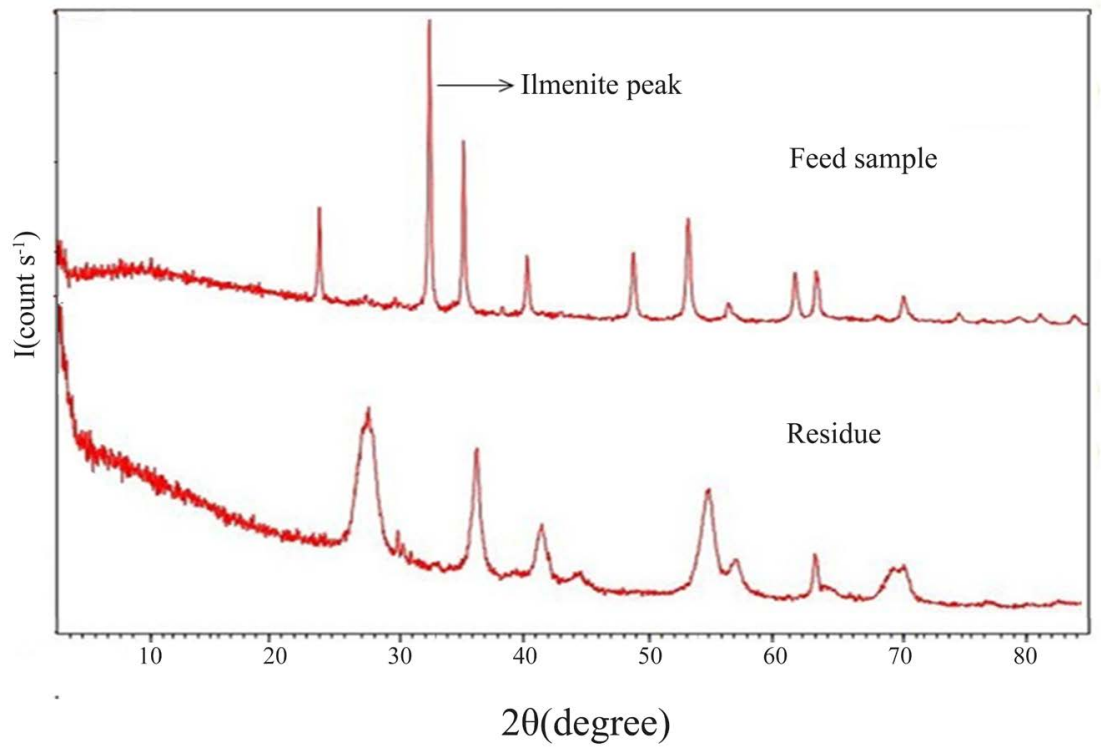

Figure 9. XRD pattern of the feed sample and leaching residue.

Also, the high concentration of oxalic acid results in the increasing the dissolution of Fe. This was due to some properties of oxalic acid in comparison to hydrochloric acid, including good chelating agent, high capacity in Fe mobilization, forming a strong bidentate ligand with Lewis acid Fe centers, labilizing the $\mathrm{Fe}-\mathrm{O}$ bond, and facilitating the electron transfer between dissolved Fe(II) and 
surface Fe(III).

The results of analysis of variance (ANOVA) demonstrated that prediction of the model for dissolution of $\mathrm{Fe}$ and $\mathrm{Ti}$ in a mixture of oxalic acid and hydrochloric acid solution is significant. This was due to the p-value of the model that is less than 0.001. Also, the software predicted the optimum condition for maximum dissolution of $\mathrm{Fe}$ and minimum dissolution of Ti with desirability of 0.745 . Applying these conditions resulted in a product with $97.15 \%$ Fe dissolution and $2.8 \%$ Ti dissolution.

For validating the model under optimum conditions of factors, leaching experiments were performed. Five confirmation tests were carried out under predicting optimum conditions, including oxalic acid to hydrochloric acid ratio 2, acid concentration: $30 \%, \mathrm{~L} / \mathrm{S}$ ratio: 9 , temperature: $160^{\circ} \mathrm{C}$, time: $3 \mathrm{~h}$. Finally, the mean value of $\mathrm{Fe}$ and $\mathrm{Ti}$ dissolution for five tests reached $97.58 \%$ and $2.43 \%$, respectively, which are very close to the predicted values. Therefore, the results of the model showed that the optimization of leaching conditions was successfully performed for producing the synthetic rutile. On the other hand, there is some inadequate information about the interaction and mechanism of the solvents on the dissolution of different elements from ores. On behalf of these results, this investigation can be a good project with an eye on the potential of mixed organic and inorganic acids as the solvent in the leaching process for researchers.

\section{Conflicts of Interest}

The authors declare no conflicts of interest regarding the publication of this paper.

\section{References}

[1] Deer, W., Howie, R. and Zussman, J. (1992) An Introduction to the Rock-Forming Minerals. Vol. 2. Longman Scientific \& Technical, Hong Kong.

[2] Didenko, P. and Efremov, A. (2004) SIMS Study of Self-Consisted Fractionation of Iron and Titanium Isotopes in Ilmenite. Applied Surface Science, 231, 903-906. https://doi.org/10.1016/j.apsusc.2004.03.165

[3] Pownceby, M., Sparrow, G. and Fisher-White, M. (2008) Mineralogical Characterisation of Eucla Basin Ilmenite Concentrates-First Results from a New Global Resource. Minerals Engineering, 21, 587-597. https://doi.org/10.1016/j.mineng.2007.11.011

[4] Nafziger, R. and Elger, G. (1987) Preparation of Titanium Feedstock from Minnesota Ilmenite by Smelting and Sulfation-Leaching. US Bureau of Mines. Report of Investigation, 9065.

[5] Walpole, E. (1997) The Austpac ERMS and EARS Processes. A Cost Effective Route to High Grade Synthetic Rutile and Pigment Grade $\mathrm{TiO}_{2}$. Heavy Minerals, 169-174.

[6] Samal, S. (2016) Synthesis and Characterization of Titanium Slag from Ilmenite by Thermal Plasma Processing. JOM, 68, 2349-2358.

https://doi.org/10.1007/s11837-016-1817-1

[7] Kotzé, H., Bessinger, D. and Beukes, J. (2006) Ilmenite Smelting at Ticor SA. Journal of the South African Institute of Mining and Metallurgy, 106, 165-170. 
[8] Balderson, G. and Macdonald, C. (1999) Method for the Production of Synthetic Rutile. Tiomin Resources, Inc., Assignee. US Patent 5885324.

[9] Sinha, H. (1979) Proceedings of the Eleventh Commonwealth Mining and Metallurgical Congress. Institute of Mining and Metallurgy, London, 669-672.

[10] Lalasari, L.H., Subagja, R., Yuwono, A.H., Firdiyono, F., Harjanto, S. and Suharno, B. (2013) Sulfuric Acid Leaching of Bangka Indonesia Ilmenite Ore and Ilmenite Decomposed by NaOH. Advanced Materials Research, 789, 522-530. https://doi.org/10.4028/www.scientific.net/AMR.789.522

[11] Baba, A., Swaroopa, S., Ghosh, M. and Adekola, F. (2013) Mineralogical Characterization and Leaching Behavior of Nigerian Ilmenite Ore. Transactions of Nonferrous Metals Society of China, 23, 2743-2750. https://doi.org/10.1016/S1003-6326(13)62792-2

[12] Zhang, W., Zhu, Z. and Cheng, C. (2011) A Literature Review of Titanium Metallurgical Processes. Hydrometallurgy, 108, 177-188. https://doi.org/10.1016/j.hydromet.2011.04.005

[13] Nayl, A. and Aly, H. (2009) Acid Leaching of Ilmenite Decomposed by KOH. Hydrometallurgy, 97, 86-93. https://doi.org/10.1016/j.hydromet.2009.01.011

[14] Zhang, L., Hu, H., Wei, L., Chen, Q. and Tan, J. (2010) Hydrochloric Acid Leaching Behaviour of Mechanically Activated Panxiilmenite $\left(\mathrm{FeTiO}_{3}\right)$. Separation and Purification Technology, 73, 173-178. https://doi.org/10.1016/j.seppur.2010.03.022

[15] Nayl, A., Awwad, N. and Aly, H. (2009) Kinetics of Acid Leaching of Ilmenite Decomposed by KOH: Part 2. Leaching by $\mathrm{H}_{2} \mathrm{SO}_{4}$ and $\mathrm{C}_{2} \mathrm{H}_{2} \mathrm{O}_{4}$. Journal of Hazardous Materials, 168, 793-799. https://doi.org/10.1016/j.jhazmat.2009.02.076

[16] Imahashi, M. and Takamatsu, N. (1976) The Dissolution of Titanium Minerals in Hydrochloric and Sulfuric Acids. Bulletin of the Chemical Society of Japan, 6, 1549-1553. https://doi.org/10.1246/bcsj.49.1549

[17] Xu, S. and Huang, Z.S. (1993) The Kinetics of Panzhihua Ilmenite Leaching with Sulfuric Acid. Mining and Metallurgical Engineering, 13, 44-48.

[18] Martínez-Luévanos, A., Rodriguez-Delgado, M.G., Uribe-Salas, A., Carrillo-Pedroza, F.R. and Osuna-Alarcón, J.G. (2011) Leaching Kinetics of Iron from Low Grade Kaolin by Oxalic Acid Solutions. Applied Clay Science, 51, 473-477. https://doi.org/10.1016/j.clay.2011.01.011

[19] Veglio, F., Passariello, B., Barbaro, M., Plescia, P. and Marabini, A.M. (1998) Drum Leaching Tests in Iron Removal from Quartz Using Oxalic and Sulphuric Acids. International Journal of Mineral Processing, 54, 183-200. https://doi.org/10.1016/S0301-7516(98)00014-3

[20] Jonglertjunya, W., Rattanaphan, S. and Tipsak, P. (2014) Kinetics of the Dissolution of Ilmenite in Oxalic and Sulfuric Acid Solutions. Asia-Pacific Journal of Chemical Engineering, 9, 24-30. https://doi.org/10.1002/apj.1742

[21] Ilhan, S., Kalpakli, A.O., Kahruman, C. and Yusufoglu, I. (2013) The Investigation of Dissolution Behavior of Gangue Materials during the Dissolution of Scheelite Concentrate in Oxalic Acid Solution. Hydrometallurgy, 136, 15-26. https://doi.org/10.1016/j.hydromet.2013.02.013

[22] Lee, S., Tran, T., Park, Y.Y., Kim, S.J. and Kim, M.J. (2006) Study on the Kinetics of Iron Oxide Leaching by Oxalic Acid. International Journal of Mineral Processing, 80, 144-152. https://doi.org/10.1016/j.minpro.2006.03.012

[23] Chen, H. and Grassian, V. (2013) Iron Dissolution of Dust Source Materials during Simulated Acidic Processing: The Effect of Sulfuric, Acetic, and Oxalic Acids. Envi- 
ronmental Science \& Technology, 47, 10312-10321.

[24] Haaland, D. (1989) Experimental Design in Biotechnology. Marcel Dekker Inc., New York.

[25] Montgomery, D. (1991) Design and Analysis of Experiments. 3rd Edition, John Wiley and Sons, New York.

[26] Mannan, S., Fakhru'l-Razi, A. and Alam, M. (2007) Optimization of Process Parameters for the Bioconversion of Activated Sludge by Penicillium corylophilum, Using Response Surface Methodology. Journal of Environmental Sciences, 19, 23-28. https://doi.org/10.1016/S1001-0742(07)60004-7

[27] Anderson, M.J. and Whitcomb, P.J. (2000) DOE Simplified: Practical Tools for Effective Experimentation. Quality and Reliability Engineering International, Oregon.

[28] Vogel, A.I. (1978) A Textbook of Quantitative Inorganic Analysis. 4th Edition, Longman, London.

[29] Lasheen, T. (2005) Chemical Benefication of Rosetta Ilmenite by Direct Reduction Leaching. Hydrometallurgy, 76, 123-129. https://doi.org/10.1016/j.hydromet.2004.10.002

[30] Suter, D., Siffert, C., Sulzberger, B. and Stumm, W. (1988) Catalytic Dissolution of Iron (III) (Hydr)oxides by Oxalic Acid in the Presence of Fe (II). Naturwissenschaften, 75, 571-573. https://doi.org/10.1007/BF00377723

[31] El-Hazek, N., Lasheen, T., El-Sheikh, R. and Zaki, S.A. (2007) Hydrometallurgical Criteria for $\mathrm{TiO}_{2}$ Leaching from Rosetta Ilmenite by Hydrochloric Acid. Hydrometallurgy, 87, 45-50. https://doi.org/10.1016/j.hydromet.2007.01.003

[32] Sasikumar, C., Rao, D., Srikanth, S., Mukhopadhyay, N.K. and Mehrotra, S.P. (2007) Dissolution Studies of Mechanically Activated Manavalakurichi Ilmenite with $\mathrm{HCl}$ and $\mathrm{H}_{2} \mathrm{SO}_{4}$. Hydrometallurgy, 88, 154-169.

https://doi.org/10.1016/j.hydromet.2007.03.013

[33] Van Dyk, J., Vegter, N. and Pistorius, P. (2002) Kinetics of Ilmenite Dissolution in Hydrochloric Acid. Hydrometallurgy, 65, 31-36.

https://doi.org/10.1016/S0304-386X(02)00063-4

[34] Mehdilo, A. and Irannajad, M. (2012) Iron Removing from Titanium Slag for Synthetic Rutile Production. Physicochemical Problems of Mineral Processing, 48, 425-439.

[35] Mahmoud, M., Afifi, A. and Ibrahim, I. (2004) Reductive Leaching of Ilmenite Ore in Hydrochloric Acid for Preparation of Synthetic Rutile. Hydrometallurgy, 73, 99-109. https://doi.org/10.1016/j.hydromet.2003.08.001 